\title{
Evaluation of Microsatellite Instability and Apoptosis in Gall Bladder Malignancy from Patients of a Cohort Exposed to Methylisocyanate
}

Suresh Kumar Jatawa* and Archana Tiwari

School of Biotechnology, Rajiv Gandhi Proudyogiki Vishwavidyalaya, Bhopal, India

${ }^{*}$ Corresponding author: Suresh Kumar Jatawa, Senior Research Fellow, School of Biotechnology, Rajiv Gandhi Proudyogiki Vishwavidyalaya, Airport Bypass Road, Bhopal 462033, India, Tel: +91-755-2678873; Fax: +91-755-2742006; E-mail: suresh_jatawa@yahoo.com

Received date: Feb 03, 2014; Accepted date: Apr 28, 2014; Published date: May 08, 2014

Copyright: (C) 2014 Jatawa SK, et al. This is an open-access article distributed under the terms of the Creative Commons Attribution License, which permits unrestricted use, distribution, and reproduction in any medium, provided the original author and source are credited.

\begin{abstract}
The molecular alterations are considered to play an important role in the both carcinogenesis and biological behavior of a variety of human malignancies. However, cancer of gallbladder is an obscured phenomenon and highly malignant with a poor survival due to underprivileged diagnosis. Tissues of 92 cases of gallbladder cancer patients (31 men and 61 women, age range 16-85 yrs, mean age $45.83 \pm 1.50 \mathrm{yrs}$ ) were examined for microsatellite instability (MSI) of six microsatellite markers (D16S539, D13S317, D7S820, F13A01, FES/FPS, vWA) and apoptosis of malignant epithelial cells through M30CytoDEATH assay. Analysis of microsatellite markers revealed $08.7 \%$ $(08 / 92)$ in gallbladder cancer, in which $10.0 \%(07 / 70)$ instability found in adenocarcinoma. The sensitivity of this test in adenocarcinoma, adenosquamous carcinaoma and adenoma with dysplasia was found to be $10.0 \%, 00.0 \%$ and $08.3 \%$ respectively suggesting its role in the multistage disease invasiveness. The immunohistochemical examination confirmed the presence of CK18 in moderately, well and poorly differentiated adenocarcinoma with the frequency of viz., $18.8 \%, 15.4 \%$ and $11.1 \%$ respectively showing positive sign of apoptosis. The mixed chimerism of STR loci and positive staining of caspase cleaved CK18 in epithelial cells of the gallbladder cancer tissues showed their independent and noteworthy character in the gallbladder carcinogenesis. Further investigations are in progress to undertake similar studies on archived tumor tissues of varied origins and forms. These might also provide modalities to translate forceful and reproducible strategies for defined clinical utility.
\end{abstract}

Keywords: Carcinogenesis; Adenocarcinoma; Adenosquamous carcinoma; Adenoma with dysplasia; Microsatellite instability; Apoptosis

\section{Introduction}

Gene expression profiling offers a great opportunity for studying multi factor diseases and for understanding the key role of genes in mechanisms which drive a normal cell to a cancer state [1] Gastrointestinal malignancy is the major cause of death worldwide in which gallbladder cancer has a unique position in this regard. Much of the understanding of the genetics of gastrointestinal tract carcinogenesis has come from analyzing various histologic stages of tumors. However, genomic instability provides a permissive environment for growth advantages on transformed cells. As neoplasia originates from a single cell that has developed a genetic alteration, and then grows at variable rates to large sizes with differing histologic morphology. Despite the many checkpoints and repair processes the cell has in place to prevent the occurrence and propagation of errors, genomic instability is a widespread phenomenon observed in many cancers [2]. Environmental agents are able to instigate the process of instability. Isocyanates are a group of low molecular weight aromatic and aliphatic compounds which are highly reactive industrial intermediates, due to their electron loving chemistry, possess the capability to modulate the biomolecules by forming toxic adducts and metabolites which may cause adverse health effects [3]. Renewed hypothesis in the evolution of these cancers suggests genomic instability as the disease hallmark and has been shown to precede cancerous transformation in several systems examined with the implication that it might be the cause rather than the consequence of malignancy [4]. Therefore, genomic instability is a fundamental feature of solid tumors, and understanding genomic instability should significantly clarify the process of tumorigenesis [5]. Substantial evidence in literature suggests these cancers follow at least two major genomic instability pathways, microsatellite instability (MSI) and chromosomal instability (CIN), wherein MSI is responsible for welldefined subset, CIN, represents a more common pathway comprising heterogeneous subsets of these cancers [6]. The connection between MSI phenotype is well established whereas the possibility of CIN as a causative link with sporadic cases still remains circumstantial [7].

Microsatellites are the class of repetitive DNA sequences present in all organisms, both Prokaryotes [8] and Eukaryotes [9]. They consist of tandemly arranged repeats of several nucleotides, MSI is the alteration of the length of simple repetitive sequences (microsatellites) throughout the genome. The detection of microsatellite instability has been considered as an indicator of defective mismatch repair (MMR) function in many tumour types [10]. Simple sequence or short tandem repeats (STRs) are segments of tandemly repeated DNA with repeat lengths up to about 6 basepair (bp) and with total lengths usually $<60$ bp. Hundreds of thousands of STRs are interspersed throughout mammalian genomes. STRs are of special interest because the numbers of repeats within specific STRs tend to be highly variable and because these short tandem repeat polymorphisms (STRPs) can be rapidly analyzed using PCR. Thousands of STRPs have been developed and mapped for the human, mouse, rat, and other genomes, and STRPs have been used to map dozens of genes responsible for heritable disorders [11,12]. By the time, gall bladder cancer is diagnosed; resection remains the only way to rescue [13] which initiated us to take a step ahead for the validation of possible molecular biomarkers that has not been determined yet. This work is an 
extension of our previous study in which we observed variable frequency of aberrant expression of cell cycle regulatory proteins in gallbladder cancer tissues [14]. Earlier, we reported a significant higher prevalence of cancer of gall bladder (CAGB) amongst victims of Bhopal gas tragedy exposed to methyl isocyanate. Therefore, there was an urgent need to understand the detailed retrospective determination of microsatellite instability and apoptosis for the validation of potential biomarkers for translational modalities in archived CAGB tissue samples among the victims of Bhopal gas tragedy, diagnosed with gall bladder malignancy. In this study, for the first time, the presence of both, Microsatellite instability by short tandem repeat PCR and apoptosis through staining of caspase cleaved cytokeratin 18 (CK18) in the tissue sections of the patients with gallbladder cancer was investigated.

\section{Materials and Methods}

\section{Materials}

Sample selection: In the present investigation cancer tissues of the gall bladder were collected from Bhopal Memorial Hospital and Research Centre (BMHRC) Raisen Bypass Road Bhopal M.P. India. CAGB is higher cancer incidences of the gastrointestinal tract noticed in the survivors of the Bhopal gas tragedy taken place in 1984. These specimens were collected after obtaining patient's informed consent, and the study was approved by the Institutional Review Board of BMHRC. Only subjects from 36 municipal wards considered "MIC affected" were selected for the study.

Tissue Specimens: The study was performed on 92 (31 men and 61 women, age range $16-85$ yrs, mean age $45.83 \pm 1.50$ yrs) surgically resected cancer tissues of gallbladder in which70 adenocarcinoma (13 well differentiated, 48 moderately differentiated and 09 poorly differentiated), 10 adenosquamous carcinoma and 12 gallbladder adenoma were examined. A gallbladder adenoma was defined as any outgrowth that histologically showed gland proliferation and some grade of dysplasia. Gallbladder adenocarcinoma was defined as an outgrowth with cells showing atypicity, forming glands and originating on superficial epithelia that can be observed microscopically. The definitions of histological classification and stage grouping were made according to the WHO International Histological Typing of Tumors [15] and the International Union against Cancer [16] respectively.

We performed this study on formalin fixed paraffin embedded gallbladder cancer specimens. All surgically resected specimens of gallbladder cancer were initially fixed in $10 \%$ neutral buffered formalin and then embedded in paraffin-wax after further dehydration processing. Then the cut sections were stained with hematoxylin and eosin. Diagnosis was based on clinical suspicion and histopathological confirmation in each patient.

\section{Methods}

\section{Microsatellite instability}

Microsatellite instability was assessed using short tandem repeat polymerase chain reaction (STR PCR). STR PCR was performed for the amplifications of six microsatellite marker loci D16S539, D13S317, D7S820, F13A01, FES/FPS, vWA using GenePrint ${ }^{\text {ix }}$ Multiplex STR Systems kit (Promega, Madison, WI, USA). Briefly, whole DNA was extracted from tissue specimens using the tissue protocol of DNeasy
Blood \& Tissue kit (QIAGEN, Germany). PCR was carried out in final volume of $25 \mu \mathrm{L}$ of reaction mix with $50 \mathrm{ng}$ of the genomic DNA, 1X PCR buffer, $200 \mu \mathrm{M}$ deoxynucleotide triphosphates, $1.5 \mathrm{mM} \mathrm{MgCl}$, $2.5 \mu \mathrm{L} 1 \mathrm{X}$ multiplex primer pair mix (Promega, Madison, WI, USA), $0.15 \mu \mathrm{L}$ of HotStar TaqTM DNA polymerase (Qiagen, Hilden, Germany). The cycling conditions were of $2 \mathrm{~min}$. initial denaturation at $94^{\circ} \mathrm{C}, 35 \mathrm{cycles}$ of $30 \mathrm{sec}$ at $94^{\circ} \mathrm{C}, 30 \mathrm{sec}$ at $50^{\circ} \mathrm{C}$, and $1 \mathrm{~min} 30 \mathrm{sec}$ at $72^{\circ} \mathrm{C}$ followed by final extension for $5 \mathrm{~min}$ at $72^{\circ} \mathrm{C}$ (Table 2). Analyses of the PCR product were done on $1 \%$ agarose gel electrophoresis (Ariffin et al., 2007). The genomic alterations were detected by the gains and losses of specific bands under Vilber Lourmat Gel Documentation Unit (Vilber Lourmat, France).

\section{M30 CytoDEATH assay}

M30cytoDEATH assay was performed to identify apoptosis. In brief deparaffinised slides were immersed in $500 \mathrm{ml}$ of pre-boiled $10 \mathrm{mM}$ citric acid buffer in microwave oven at $100 \mathrm{~W}$ for $15 \mathrm{~min}$. Slides were then being cooled down for $5 \mathrm{~min}$ at room temperature and then mounted tissues were rinsed with Phosphate Buffer Saline (PBS) for 2 min. Washed slides thereafter blocked with PBS $+1 \%$ BSA for $10 \mathrm{~min}$ at room temperature. Then M30 CytoDEATH (Peviva, Bromma, Sweden) solution were added to the slides by removing blocking solution and incubated for $1 \mathrm{hr}$ at room temperature for M30 staining. The slides were then be incubated in freshly prepared substrate solution DAB (3,3'-Diaminobenzidine) until a clearly visible colour developed, followed by washing with PBS thrice to remove unbound M30 CytoDEATH solution. The slides were now be counterstained with hematoxylin and then immediately mounted with another cover glass over the tissue. Finally the images from mounted specimen were acquired and analyzed under Spectral Bio-imaging System (AXIOSKOP 2 PLUS / ZEISS Epi-fluorescent microscope).

\section{Criteria for positive immunohistochemical staining}

The antibody M30 CytoDEATH recognizes a neo epitope formed after caspase cleavage of keratin 18 at Asp396 [17] and M30 CytoDEATH does not bind native, unmodified K18 of normal cells. Therefore, M30 CytoDEATH is a very reliable and convenient tool for demonstration of apoptosis in single cells and tissue sections of epithelial origin.

\section{Results}

\section{Microsatellite instability analysis}

Microsatellite instability (MSI) is the alteration of the length of simple repetitive sequences (microsatellites) throughout the genome. An important characteristic of most of the cancers is a striking genomic instability, leading to ongoing accumulation of mutational changes, some of which underlie tumor progression, including acquisition of invasiveness and metastasis [18].

MSI was determined from PCR amplifications of six-microsatellite marker loci (D16S539, D13S317, D7S820, F13A01, FES/FPS, vWA) using an in house standardized protocol. Cases were classified as having high-frequency MSI (MSI-H) (>/= 2 loci showing instability), low-frequency MSI (MSI-L) (only one locus showing instability), or as microsatellite stable. STR PCR results records the variable amplification of short tandem repeats in the genome. Variations at the levels of absence and increased/decreased intensity of bands have been clearly shown in the gallbladder cancer tissues (Figures 1-4). Data were 
analyzed by Biocapt software used in the Gel-Documentation unit of Vilber Lourmat, France. MSI is the alteration of the length of simple repetitive sequences (microsatellites) throughout the genome (Table $1)$.

\begin{tabular}{|c|c|c|c|c|}
\hline \multicolumn{2}{|c|}{ Pathological Features } & $\begin{array}{l}\text { Microsatellite } \\
\text { Instability Found }\end{array}$ & $\begin{array}{l}\text { Microsatellite } \\
\text { Instability Not } \\
\text { Found }\end{array}$ & $\begin{array}{l}\text { Total } \\
\text { Sample } \\
\text { s }\end{array}$ \\
\hline \multicolumn{2}{|c|}{$\begin{array}{l}\text { Gall Bladder Cancer Group } \\
\text { Exposed } \\
\text { (Cases) }\end{array}$} & $08(08.7 \%)$ & $84(91.3 \%)$ & 92 \\
\hline 2.A & Adenocarcinoma & $07(10.0 \%)$ & $63(90.0 \%)$ & 70 \\
\hline 2.B & $\begin{array}{l}\text { Adenosquamous } \\
\text { carcinoma }\end{array}$ & $00(00.0 \%)$ & $10(100.0 \%)$ & 10 \\
\hline 2.C & $\begin{array}{l}\text { Adenoma } \\
\text { Dysplasia }\end{array}$ & $01(08.3 \%)$ & $11(91.7 \%)$ & 12 \\
\hline
\end{tabular}

Table 1: Showing microsatellite instability

\section{Apoptosis analysis}

Cell death (apoptosis) mode has been studied in cancer, autoimmune, and neurodegenerative diseases. In this study, apoptosis is investigated for the first time in patients with gallbladder malignancy from a cohort exposed to MIC. The monoclonal antibody M30 CytoDEATH was used for the determination of early apoptosis in epithelium of the gallbladder cancer tissue. A specific epitope of cytokeratin18, which is presented after cleavage by caspases, led us to use immunohistochemistry examination, with the monoclonal antibody M30 CytoDeath, to detect apoptosis in the mucosa of the gallbladder tissues. The M30 CytoDeath antibody binds to a caspasecleaved formalin resistant epitope of cytokeratin 18, which is exposed during early apoptosis and not with wild type normal K18 [19]. Cells staining positive for caspase cleaved CK18 were present in the epithelial cells in the tissue of the origin of gallbladder adenocarcinoma confirming the cells were under apoptosis (Figure 5 and Table 2).

\begin{tabular}{|c|c|c|c|c|}
\hline \multicolumn{2}{|c|}{ Pathological Features } & Cell Death Found & $\begin{array}{l}\text { Cell Death } \\
\text { Not Found }\end{array}$ & Total samples \\
\hline \multicolumn{2}{|c|}{$\begin{array}{l}\text { Gall Bladder } \\
\text { Adenocarcinoma Exposed } \\
\text { Population (Cases) }\end{array}$} & $12(17.1 \%)$ & $58(82.9 \%)$ & 70 \\
\hline 2.A & $\begin{array}{l}\text { Moderately } \\
\text { differentiated } \\
\text { adenocarcinoma }\end{array}$ & $09(18.8 \%)$ & $39(81.2 \%)$ & 48 \\
\hline $2 . \mathrm{B}$ & $\begin{array}{l}\text { Well differentiated } \\
\text { adenocarcinoma }\end{array}$ & $02(15.4 \%)$ & $11(84.6 \%)$ & 13 \\
\hline 2.C & $\begin{array}{l}\text { Poorly differentiated } \\
\text { adenocarcinoma }\end{array}$ & $01(11.1 \%)$ & $08(88.9 \%)$ & 09 \\
\hline
\end{tabular}

Table 2: Showing CK18 staining for the identification of apoptosis.

\section{Discussion}

Deleterious alterations in cellular DNA result from endogenous sources of damage, as well as from external genotoxic chemicals in the environment. It is often difficult to ascertain the relative contributions of environmental sources to biological endpoints yet they are considered as high risk factors [20]. Understanding the possible link between the environmental factors and the mechanism leading to the genomic instability and cancer is a matter of serious concern as these factors are in easy touch with the mankind [21]. Isocyanates, including MIC are the chief metabolic intermediates in many industrial settings with diverse applications. Despite of their wide array of industrial applications, they also possess the capability to undergo a series of biotransformation reactions $[22,23]$ and are also known to exert mutagenic and genotoxic alterations [24-26].

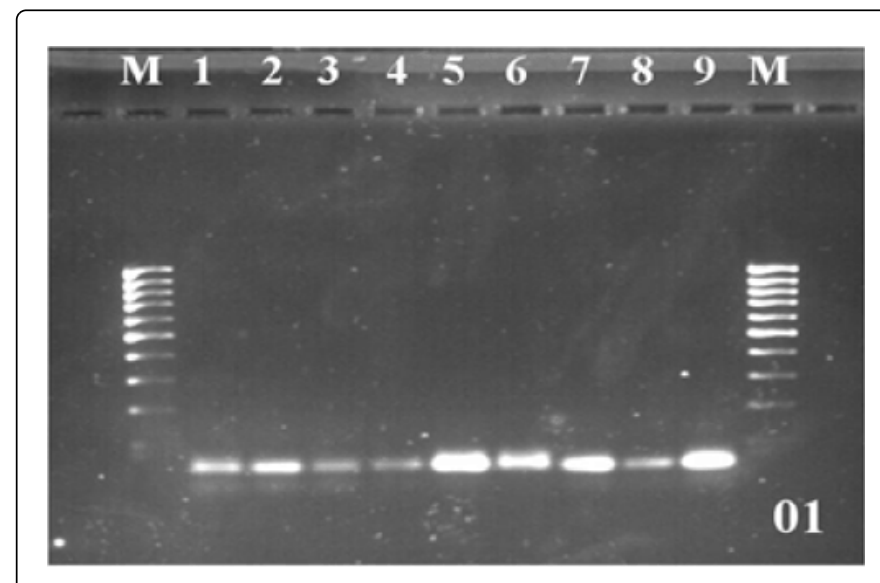

Figure 1: Microsatellite Instability for loci D16S539. Microphotograph displaying the variant banding pattern of STR loci D16S539 in CAGB subjects. Lanes M: low base pair marker (100 bp); Lane 1: control and Lane 2-9: genomic alterations were detected by variations at the levels of absence and increased/ decreased intensity of bands that have been clearly shown in the transformed cells of various samples.

Biological evolution ensures that several backup mechanisms always exist to prevent the failure of cellular processes. In response to genotoxic exposure or other adverse environmental conditions cell cycle checkpoints are initiated in an attempt to prevent the fixation of mutations from one generation to the next [27]. Microsatellite instability or genomic instability is believed to play a significant role in cancer development by facilitating tumor progression and tumor heterogeneity. Inter-simple sequence repeat (inter-SSR) PCR has been proved to be a fast and reproducible technique for quantitation of genomic instability in a variety of human tumors [28]. In addition to the specific genetic changes discussed earlier, other evidence indicates that genomic instability occurs in gallbladder malignancy. This evidence includes changes in the number of inter simple sequence DNA repeats and short-tandem DNA repeats (also known as microsatellite markers), frequently present in a wide variety of cancer types. Microsatellite instability was initially reported in hereditary non-polyposis colorectal malignancy, resulting from inherited defects in DNA mismatch repair enzymes, which induce large scale genomic instability. Another form of microsatellite change, where only a single band of altered size is found, has been described in many forms of sporadic cancers, including small cell lung carcinoma and non-small cell lung carcinoma, referred to as microsatellite alteration [29]. Its importance in bladder cancer has been recently highlighted by the observation that microsatellite analyses may also be used as a sensitive screening tool for the detection of primary gallbladder cancer. The reported prevalence of high microsatellite instability for sporadic gallbladder carcinoma ranges from 0 to $10 \%$ [30-33] correspondingly, 
Citation: Jatawa SK, Tiwari A (2014) Evaluation of Microsatellite Instability and Apoptosis in Gall Bladder Malignancy from Patients of a Cohort Exposed to Methylisocyanate. J Carcinog Mutagen 5: 171. doi:10.4172/2157-2518.1000171

Page 4 of 6

in present cases; the prevalence of microsatellite instability was accordance that reported in the literature. A variant banding pattern of STR loci D16S539 (Figure 1), D7S820 (Figure 2), D13S317 (Figure 3) and F13A01; FES/FPS, vWA loci (Figure 4) respectively examined in CAGB subjects.
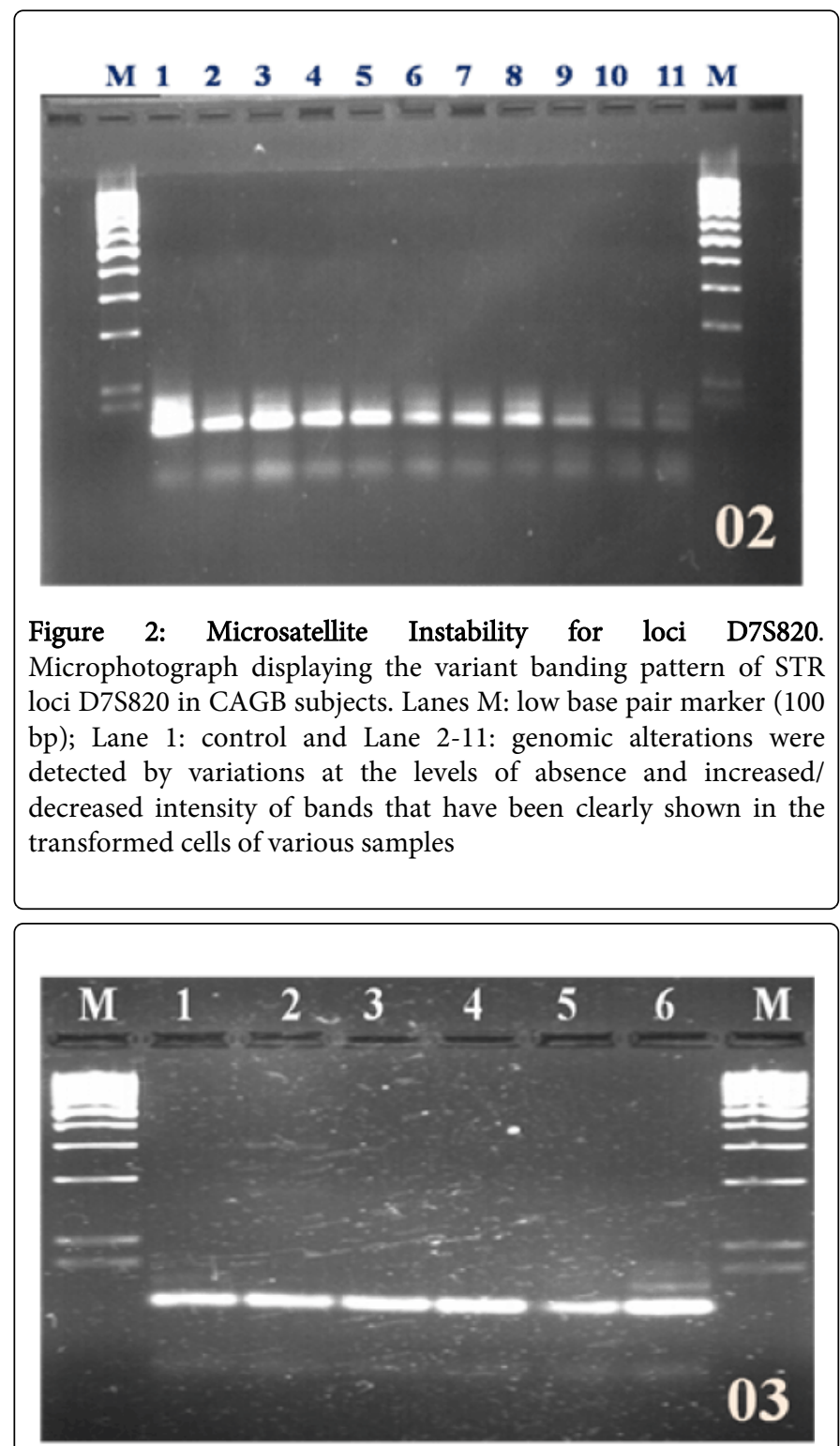

Figure 3: Microsatellite Instability for loci D13S317. Microphotograph displaying the variant banding pattern of STR loci D13S317 in CAGB subjects. Lanes M: low base pair marker (100 bp); Lane 1: control and Lane 2-6: genomic alterations were detected by variations at the levels of absence and increased/ decreased intensity of bands that have been clearly shown in the transformed cells of various samples.

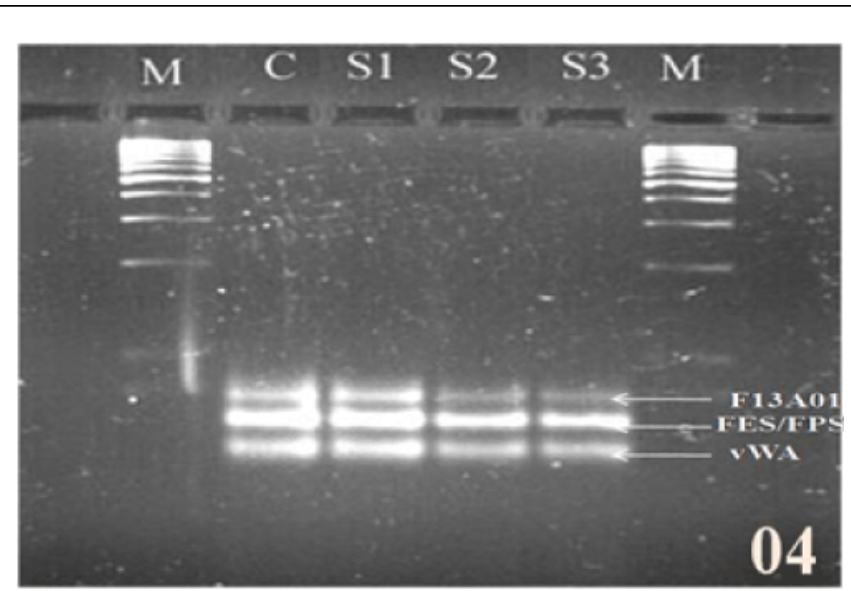

Figure 4: Microsatellite Instability for F13A01; FES/FPS and vWA loci. Microphotograph displaying the variant banding pattern of simple tandem repeat loci in CAGB subjects. Lanes M: low base pair marker (100 bp); Lane C: Control, Lane 1-3 sample of CAGB for F13A01; FES/FPS and vWA analysis.

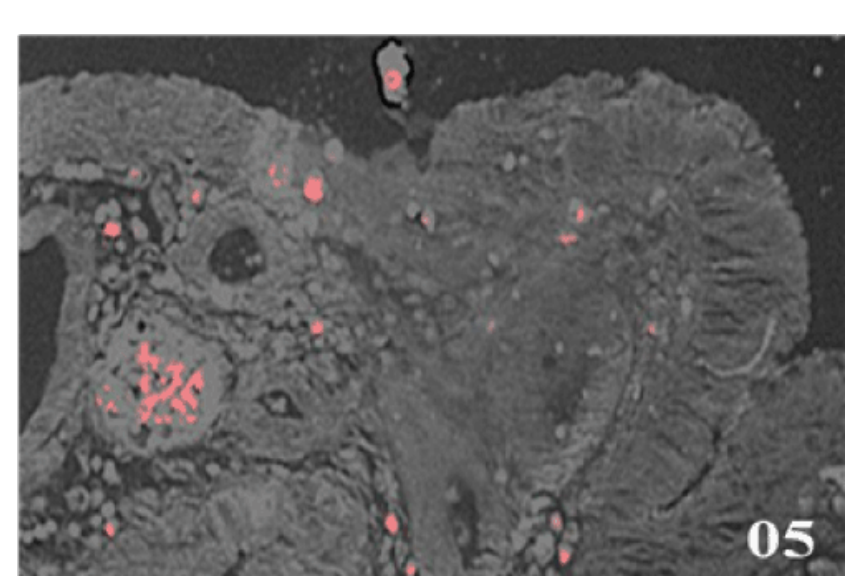

Figure 5: Photomicrograph representing the detection of apoptosis in a formalin-fixed paraffin-embedded tissue section from a human gallbladder cancer sample showing confined staining for CK18 (Pink spots) using M30CytoDEATH counterstained with hematoxylin eosin (40X).

The shift in bands observed in cases indicated genetic alterations at D16S539, D7S820, D13S317 and F13A01; FES/FPS, vWA microsatellite loci in tissues of gallbladder cancer of patients from cohort exposed to MIC. The genomic alterations were detected by variations at the levels of absence and increased/decreased intensity of bands that have been clearly shown in the gallbladder cancer tissues (Figures 1-4). The genomic instability was noticed in 08/92 (08.7\%) in gall bladder cancer tissues of the exposed population (Table 1). The sensitivity of this test in adenocarcinoma, adenosquamous carcinaoma and adenoma with dysplasia was found to be $10.0 \%, 00 \%$ and $8.3 \%$ respectively (Table 1) suggesting its role in the multistage disease invasiveness. The efficacy of any formalin fixed paraffin embedded tissues based assay depends on its sensitivity and specificity. An ideal 
Page 5 of 6

biomarker should have high sensitivity and specificity in order to accurately detect gallbladder malignancy. The specificity of this test in each cohort was found to be significant and moderate. This suggests that microsatellite instability plays a significant role in the pathogenesis of gallbladder cancer.

Furthermore, in an attempt to study the process of cell death in the epithelium of patients with adenocarcinoma of the gallbladder, the concentration of CK18 caspase mediated cleavage in the tissue sections of CAGB patients was examined. Because in adult tissues the number of cell population is determined by the rates of cell proliferation, differentiation, and cell death by apoptosis and increased cell numbers may result from either increased proliferation or decreased cell death $[34,35]$. Proliferating cells have a substantial pool of two soluble cytokeratin's, namely CK8 and CK18, and their concentration is high during the G2-M phase of the cell cycle [36]. During apoptosis, CK18 are cleaved by caspases at position Asp396 producing relatively stable fragments [37-41]. These fragments can be detected in formalin fixed paraffin embedded tissue sections being a biomarker of apoptosis, while soluble intact CK18 may be released during both necrosis and apoptosis. Although cell death is a physiologic process required for tissue homeostasis, but it can also be induced by a variety of pathologic stimuli. Therefore, cytokeratins (epithelial keratins) are an important component of the intermediate filament system. They are mainly insoluble molecules playing an important role in cellular mechanics like cell shape, motility, division and cell-cell contact $[42,43]$.

The immunohistochemistry of paraffin embedded tissue sections of gallbladder malignancy was performed to confirm the presence of apoptotic CK18 fragments with the help of M30 antibody. The presence of increased caspase cleaved CK18 serum levels in cancer patients has been recently documented, and seems to be a useful diagnostic marker for these patients. In this way, the ratio of intact CK18 may be a helpful tool in quantifying apoptosis and the cell transformation. In a prior study, the proliferative and apoptotic processes in patients with chronic cholecystitis were examined [43]. Reactive proliferation of epithelial cells was noted using the Ki67 proliferation index, accompanying a clear apoptotic tendency of the gallbladder mucosa, confirmed by the intense p21WAF1 protein expression, a downstream protein of the activated wild type p53 gene, which is a key step of the apoptotic process [44]. The finding of the present study is in full accordance with the literature, that CK18 apoptotic fragments are present $12 / 70(17.1 \%)$ in the gallbladder mucosa of patients with adenocarcinomas of the gallbladder (Table 2). Furthermore, on the differentiation grade the presence of CK18 in moderately, well and poorly differentiated adenocarcinoma were with the frequency of viz., $18.8 \%, 15.4 \%$ and $11.1 \%$ respectively (Table 2 ) showing positive sign of apoptosis, with significant presence of caspase cleaved CK18 in epithelial cells of the gallbladder cancer tissues (Figure 5). In conclusion, with the present study it could be concluded that the microsatellite instability may have an important and independent role in the process of gall bladder carcinogenesis and significant relationships independently with tumor type and stage. The positive staining for caspase cleaved CK18 in gallbladder epithelial cells suggest clearly the cells are under apoptosis and it could be of clinical usefulness to identify patients with gall bladder carcinogenesis. These results imply that the level of caspase cleaved CK18, and some of STR loci could be a biomarker for the sign of initiation of cholecystitis and development of gallbladder malignancy.

\section{Acknowledgement}

The authors are thankful to University Grants Commission, New Delhi, India for providing financial support for the study and to Bhopal Memorial Hospital and Research Center, Bhopal, India for facilitating the necessary support to investigation.

\section{Reference}

1. Biological and functional analysis of statistically significant pathways deregulated in colon cancer by using gene expression profiles. Int J BiolSci: 368-378.

2. Perera S, Bapat B (2007) Genetic Instability in Cancer. Atlas Genet Cytogenet Oncol Haematol.

3. Tamura N, Aoki K, Lee MS (1992) Selective reactivities of isocyanates towards DNA bases and genotoxicity of methylcarbamoylation of DNA. Mutat Res 283: 97-106.

4. Chen N, Stoler DL, Dutt SS, Jahreis GP, Rodriguez-Bigas MA, et al. (2005) Analysis of inter-(simple sequence repeat) PCR products from human colorectal cancers. Oncol Res 15: 233-238.

5. Morgante M, Hanafey M, Powell W (2002) Microsatellites are preferentially associated with nonrepetitive DNA in plant genomes. Nat Genet 30: 194-200.

6. Ottini L, Falchetti M, Lupi R, Rizzolo P, Agnese V, et al. (2006) Patterns of genomic instability in gastric cancer: clinical implications and perspectives. Ann Oncol 17 Suppl 7: vii97-102.

7. Yokozaki H, Yasui W, Tahara E (2001) Genetic and epigenetic changes in stomach cancer. Int Rev Cytol 204: 49-95.

8. Gur-Arie R, Cohen CJ, Eitan Y, Shelef L, Hallerman EM, et al. (2000) Simple sequence repeats in Escherichia coli: abundance, distribution, composition, and polymorphism. Genome Res 10: 62-71.

9. Saetta AA, Goudopoulou A, Korkolopoulou P, Voutsinas G, ThomasTsagli E, et al. (2004) Mononucleotide markers of microsatellite instability in carcinomas of the urinary bladder. Eur J Surg Oncol 30: 796-803.

10. Hearne CM, Ghosh S, Todd JA (1992) Microsatellites for linkage analysis of genetic traits. Trends Genet 8: 288-294.

11. Campbell DB, Hess EJ (1997) Rapid genotyping of mutant mice using dried blood spots for polymerase chain reaction (PCR) analysis. Brain Res Brain Res Protoc 1: 117-123.

12. Lazcano-Ponce EC, Miquel JF, Muñoz N, Herrero R, Ferrecio C, et al. (2001) Epidemiology and molecular pathology of gallbladder cancer. CA Cancer J Clin 51: 349-364.

13. Mishra PK, Dabadghao S, Modi GK, Desikan P, Jain A, et al. (2009) In utero exposure to methyl isocyanate in the Bhopal gas disaster: evidence of persisting hyperactivation of immune system two decades later. Occup Environ Med 66: 279.

14. Albores-Saavedra J, Henson DE, Sobin LH (1992) The WHO Histological Classification of Tumors of the Gallbladder and Extrahepatic Bile Ducts. A commentary on the second edition. Cancer 70: 410-414.

15. Beahrs OH, Henson D E, Hutter R V P, Kennedy B J (eds.)(1992) Manual for Staging of Cancer [Ed. 4], J B Lippincott Co, Philadelphia, USA

16. Leers MP, Kölgen W, Björklund V, Bergman T, Tribbick G, et al. (1999) Immunocytochemical detection and mapping of a cytokeratin 18 neoepitope exposed during early apoptosis. J Pathol 187: 567-572.

17. Shammas MA, Shmookler Reis RJ, Koley H, Batchu RB, Li C, et al. (2009) Dysfunctional homologous recombination mediates genomic instability and progression in myeloma. Blood 113: 2290-2297. 
18. Macha MA, Matta A, Sriram U, Thakkar A, Shukla NK, et al. (2010) Clinical significance of TC21 overexpression in oral cancer. J Oral Pathol Med 39: 477-485.

19. Hanawalt PC (1998) Genomic instability: environmental invasion and the enemies within. Mutat Res 400: 117-125.

20. Lichtenstein P, Holm NV, Verkasalo PK, Iliadou A, Kaprio J et al.(2000) Environmental and heritable factors in the causation of canceranalyses of cohorts of twins from Sweden, Denmark, and Finland. N Engl J Med 13:78-85.

21. Pearson PG, Slatter JG, Rashed MS, Han DH, Grillo MP, et al. (1990) S(N-methylcarbamoyl)glutathione: a reactive S-linked metabolite of methyl isocyanate. Biochem Biophys Res Commun 166: 245-250.

22. Slatter JG, Rashed MS, Pearson PG, Han DH, Baillie TA (1991) Biotransformation of methyl isocyanate in the rat. Evidence for glutathione conjugation as a major pathway of metabolism and implications for isocyanate-mediated toxicities. Chem Res Toxicol 4: 157-161.

23. Mason JM, Zeiger E, Haworth S, Ivett J, Valencia R (1987) Genotoxicity studies of methyl isocyanate in Salmonella, Drosophila, and cultured Chinese hamster ovary cells. Environ Mutagen 9: 19-28.

24. Anderson D, Goyle S, Phillips BJ, Tee A, Beech L, et al. (1988) Effects of methyl isocyanate on rat muscle cells in culture. Br J Ind Med 45: 269-274.

25. Kar RN, Khan KA, Sethi N (1989) Genotoxicity studies on mice after short term inhalation exposure to methyl isocyanate. Cytobios 59: 167-176.

26. Zhou BB, Elledge SJ (2000) The DNA damage response: putting checkpoints in perspective. Nature 408: 433-439.

27. Benavides F, Zamisch M, Flores M, Campbell MR, Andrew SE, et al. (2002) Application of inter-simple sequence repeat PCR to mouse models: assessment of genetic alterations in carcinogenesis. Genes Chromosomes Cancer 35: 299-310.

28. Loeb LA (1994) Microsatellite instability: marker of a mutator phenotype in cancer. Cancer Res 54: 5059-5063.

29. Yoshida T, Sugai T, Habano W, Nakamura S, Uesugi N, et al. (2000) Microsatellite instability in gallbladder carcinoma: two independent genetic pathways of gallbladder carcinogenesis. J Gastroenterol 35: 768-774.

30. Rashid A, Ueki T, Gao YT, Houlihan PS, Wallace C, et al. (2002) K-ras mutation, p53 overexpression, and microsatellite instability in biliary tract cancers: a population-based study in China. Clin Cancer Res 8 : 3156-3163.
31. Yanagisawa N, Mikami T, Yamashita K, Okayasu I (2003) Microsatellite instability in chronic cholecystitis is indicative of an early stage in gallbladder carcinogenesis. Am J Clin Pathol 120: 413-417.

32. Roa JC, Roa I, Correa P, Vo Q, Araya JC, et al. (2005) Microsatellite instability in preneoplastic and neoplastic lesions of the gallbladder. J Gastroenterol 40: 79-86.

33. Pellettieri J, Sánchez Alvarado A (2007) Cell turnover and adult tissue homeostasis: from humans to planarians. Annu Rev Genet 41: 83-105.

34. Ott HC, Matthiesen TS, Goh SK, Black LD, Kren SM, et al. (2008) Perfusion-decellularized matrix: using nature's platform to engineer a bioartificial heart. Nat Med 14: 213-221.

35. Chou CF, Riopel CL, Rott LS, Omary MB (1993) A significant soluble keratin fraction in 'simple' epithelial cells. Lack of an apparent phosphorylation and glycosylation role in keratin solubility. J Cell Sci $105: 433-444$.

36. Ku NO, Liao J, Omary MB (1997) Apoptosis generates stable fragments of human type I keratins. J Biol Chem 272: 33197-33203.

37. Caulín C, Salvesen GS, Oshima RG (1997) Caspase cleavage of keratin 18 and reorganization of intermediate filaments during epithelial cell apoptosis. J Cell Biol 138: 1379-1394.

38. Kerr JF (1971) Shrinkage necrosis: a distinct mode of cellular death. J Pathol 105: 13-20

39. Makin G, Hickman JA (2000) Apoptosis and cancer chemotherapy. Cell Tissue Res 301: 143-152.

40. Ueno T, Toi M, Linder S (2005) Detection of epithelial cell death in the body by cytokeratin 18 measurement. Biomed Pharmacother 59 Suppl 2: S359-362.

41. Simopoulos C, Tsaroucha AK, Asimakopoulos B, Giatromanolaki A, Gavriilidis P, et al. (2008) Total and caspase-cleaved cytokeratin 18 in chronic cholecystitis: a prospective study. BMC Gastroenterol 8: 14.

42. Moll R, Franke WW, Schiller DL, Geiger B, Krepler R (1982) The catalog of human cytokeratins: patterns of expression in normal epithelia, tumors and cultured cells. Cell 31: 11-24.

43. Yanagisawa N, Mikami T, Koike M, Okayasu I (2000) Enhanced cell kinetics, p53 accumulation and high p21WAF1 expression in chronic cholecystitis: comparison with background mucosa of gallbladder carcinomas. Histopathology 36: 54-61.

44. Xiong Y, Hannon GJ, Zhang H, Casso D, Kobayashi R, et al. (1993) p21 is a universal inhibitor of cyclin kinases. Nature 366: 701-704. 